\title{
A NEW FILM LANGUAGE: “AMATEUR VIDEO"
}

\author{
H. Hale KÜNÜÇEN \\ Başkent Üniversitesi, İletişim Fakültesi, Ankara \\ kunucen@baskent.edu.tr \\ Kağan OLGUNTÜRK \\ Bilkent Üniversitesi, Güzel Sanatlar, Tasarım ve Mimarlık Fakültesi, Ankara \\ kagan@bilkent.edu.tr
}

\begin{abstract}
Film making has been a very expensive hobby for ameteurs from the day it was discovered. Also it has not been taken as a professional tool for years. Especially after Griffth's approaches on camera movements, camera angles, framing techniques such as medium shot or close-up. The quality level of filmmaking between amateurs and professionals has been highly spread. Today, by the help of new technologies these two fields got closer. Now we can make near-professional films by using amateur equipments; we can edit them at our home computer, we can even prepare some music at home by using the help of some softwares. Also we can freely share it by using websites such as Youtube, Vimeo or some others. So for amateurs its not only easy and cheap to produce a film but also it is easy and cheap to distribute it. The number of amateur movies produced today are much more then professional movies. The enormous number of amateur productions also affected the audience and created "a new way" of story telling like shaked camera movements, deficient lighting, grainy look. This way of story telling first was discomforting and disorienting for the audience, but later they got used to it. This also affected the professionals: lots of production firms started to make professional films which used 'amateur way' of story telling. This study intends to discuss this new way of telling a story and implications associated with this new approach. The discussion will focus on three selected professional films using this new approach, namely "District 9" (2009), "Cloverfield" (2008) and "Paranormal Activity" (2007). These films use jump-cuts, deficient lighting and grainy pictures, contrasting strongly with traditional way of story telling. Thus, the study will explore the important points of using editing applications, lighting, image composition and camera movements with their relationship to the existing cinematography, trying to find an explanation to this new perception of reality in digitalization.
\end{abstract}

Keywords: The elements of cinema, language of traditional cinema, Amateur video, Digital moviemaking.

\section{INTRODUCTION}

Filmmaking has been a very expensive hobby for amateurs from the day it was discovered. Also it has not been taken as a profession for years, until D.W. Griffth's approaches on camera movements, editing, camera angles and framing techniques such as medium shot or close-up. The quality level of film making between amateurs and professionals has been highly spread. Today, by the help of new technologies these two fields got closer. Now we can make near-professional films by using amateur equipments: we can edit them at our home computer, we can even prepare some music at home by using the help of some softwares. Also we can freely share it by using websites such as Youtube, Vimeo or some others. So, for amateurs it is not only easy and cheap to produce a film, but also it is easy and cheap to distribute it. The number of amateur movies produced today is much higher than the number of professional movies. The enormous number of amateur productions also affected the audience and created "a new way" of story telling like shaky camera movements, deficient lighting and grainy look. This way of story telling first was discomforting and disorienting for the audience, but later they got used to it. This also affected the professionals; lots of 
production firms started to make professional films, which used 'amateur way' of story telling.

\section{CLASSICAL NARRATIVE}

Classical narrative is based on continuity editing. In continuity editing the cuts should not take the attention of audience, that's why best cut was used to be the invisible cut where film editing was also called the invisible art. To construct a lucid continuity the first aim is to find a way to make a smooth cut. Making a smooth cut means cutting two neighbor frames in a way that the cut should not take unnecessary attention (1). Especially, the word "seamlessness" has become a popular term in effective film editing. An invisible cut is the first goal of a director or an editor. It is not easy to describe the appropriate cut point but the audience definitely understands when it is inappropriate. Filmmakers call these inappropriate cuts "jump-cuts" and the director must take care of "matching action", "matched framing", "screen direction", "similar setting" and "tone, rhythm and pace" (2).

\subsection{Matching action}

If a man is shot when walking into a room and if we see him sat on a chair the other frame that cut would definitely take attention and the illusion of continuity will be broken (3). That's why the director should show the man while sitting down for not letting his audience to be interrupted by the cut.

\subsection{Matched framing, similar setting, screen direction}

Cutting someone from long shot to a mid-shot, the director should think about how to frame his actor. Cutting from long shot of a man to another long shot of the same character would be noticeable because the visual information would not be changing enough. Cutting the neighbor framings would not be enough as the director should choose from long shot to medium, close up to get enough change in the visual information. Another thing that should not be forgotten is to change the position of the camera to at least 30 degrees. That's how we can change the visual information in the background (4). The light and color should not change in between shots for continuity editing. The exposure and the color temperature for each shot should be similar. Also, the screen direction is very important for continuity editing. The character should move to the same direction in each shot unless he changes his walking direction, and even if he changes his direction the change should be shown to the viewer. If a director shoots a film b using a classical narrative style he or she should take the topics which were told above into considration. The purpose of classical narrative is to create and emotinoal reaction on the audience when its first screening. Thats why the viewer should forget that he or she is watching a film. When ever there is a noticable cut it will not be easy to create the desired emotinal reaction.

\section{3. "A NEW WAY" OF STORY TELLING}

From the director's point of view there seems like having two main problems; first one is the reason for using amateur video look in a professionally produced film. The second one is to legalize the usage of amateurish camera movements and editing. Before answering these questions we should discuss what the principles of amateur approach are. As most filmmakers know, classical narrative is based on continuity editing. One of the most important purposes of using continuity editing is to convert real time into screen time without distracting the audience or confusing them (3). That's why the audience will be seeing fragments from a scene but still will not lose the illusion of continuity. By the help of continuity editing the viewer can feel emotionally connected to the main character, then he would feel the tension and in the end of the film the director will be able to get the emotional reaction from the viewer. The main purpose of filmmaking, which uses classical narrative, is to get an emotional reaction from the audience not a critical one. 


\subsection{Why and how filmmakers use this approach}

As mentioned before the first problem is the reason to use this new approach. Amateurs most likely shoot the way they like. Very few of them have the knowledge about composition, lighting, and basic cinematography. The word "amateur" comes from the word "love" and that's why most of them are so passionate about their works. Especially during the screening the most important advantage of this way of story telling is that it creates the atmosphere of reality. When the audience sees this type of movies, the belief in reality occurs naturally. There seems to be a big contradiction between two different ways of story telling. In continuity editing the purpose is to create the illusion of reality but with this new approach, which does not give importance to "match cutting", similar framing or similar setting creating this reality feeling seems very easy. That's why filmmakers especially the ones making horror, fantastic or science fiction movies are starting to use this approach to give the feeling of reality to their audience.

\subsection{Digitalization}

The feeling of reality is coming from the similarity between amateur works, which are being shared in video sharing web-sites such as Youtube or Vimeo and the professional works which look like them. In 1995, Sony and Panasonic both came out with a component $1 / 4$ inch digital formats designed to be used by both professional and consumers (5). (Mini DV and DVCAM from Sony and DVC-pro from Panasonic) This format was able to record excellent component digital image on a very small tape and the DV cameras were highly compatible with fire-wire connections. Most computers used for video editing have a fire-wire port or one can be easily fitted. Fire-wire connection is also called IEEE 1394 or i-link. A fire-wire cable is able to carry video signal, time-code, and deck control information easily. (Figure 1)

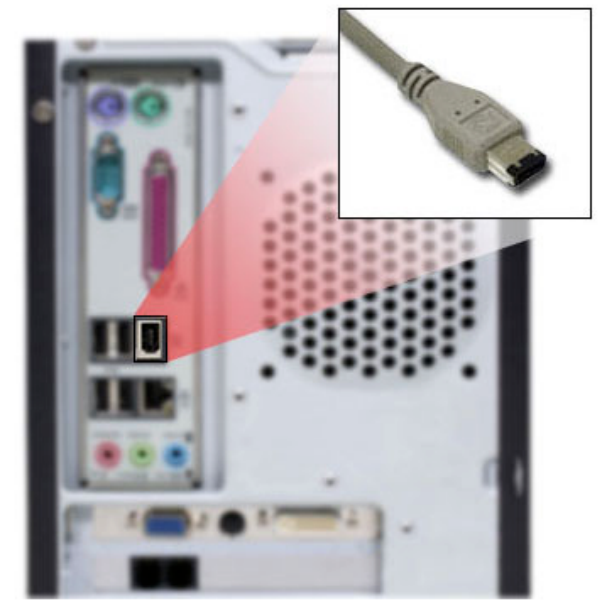

Figure 1. Fire-wire port

http://www.mycomputerclub.com/reference-cables-guide.html

The original fire-wire port was also called fire-wire 400, which was able to carry $400 \mathrm{Mbps}$. Today most computers are equipped with fire-wire 800 ports, which are able to carry 800 Mbps. By the help of this port, the amateurs are able to produce movies with much cheaper budgets. They can easily shoot their films and easily capture their footage to their home computers and edit them easily. Then they can export their films in any format they like and can share them on the Internet. Digitalization is even easier these days by the help of technology. Most video cameras are recording on SD cards. There are even some Digital photo cameras able to record high definition videos. By using the SD card technology, the filmmakers can easily use a card reader and can import or transfer their footage to their computers easily. While capturing from DV or HDV tape, capture time was the main problem. If you have a one-hour tape then the capture was taking one hour time. But with the card technology its much faster. That's why the amateurs can easily import their footage, edit it and export it to a certain media (1). Today almost all amateur video cameras and even new 
generation DSLR photo cameras are equipped with the card technology. There are several types of recording cards such as SD , P2, XD vs. All these card formats works with more or less the same system. Codec becomes an important term for video technology. Codec is short of two words Compress/Decompress. Video cameras compresses the footage to be able to record on a card. Then to be able to edit it the filmmaker should decompress the files. For example 10:1 compression ratio means $1 \mathrm{~GB}$ clip can be reduced to 100MB by using the particular compression. There are two types of compressions lossy and lossless. The lossless compression means what you put is exactly what you get out. In lossy codecs you lose some image, video or audio information. But in lossy codecs the good compressions are good at balancing the quality, data rate, file size, color depth and fluid motion (6). Most popular codecs today are H.264, AVCHD and AVCIntra. Almost all video editing softwares are compatible for these codecs.

The lack of information about classical narrative in those films prevent them from telling a story in a fluid way. There usually are several jump-cuts and mis-matching frames. After being watched by a huge audience those jumps cuts and mis-matching framing started to add some reality to those films. As every individual can easily produce similar films at home by himself, the feeling of reality is added to those amateur films. Then the latter problem occurs, the legalization of using this approach. In this study we are using one sample from each genre to discuss this. The film "Paranormal Activity" as a sample of horror films. "Cloverfield" as a sample of fantastic films and "District 9" as a sample of science fiction films. Legalization of using this approach occurs in different ways within each film.

\section{SAMPLES FOR NEW WAY OF STORY TELLING}

\subsection{The case of Paranormal Activity}

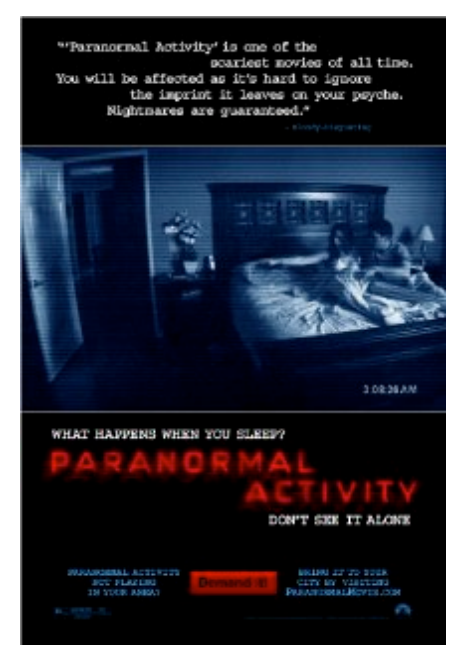

Figure 2. The poster of Paranormal Activity. http://www.imdb.com/title/tt1179904/

The film Paranormal Activity is about a young, middle class couple who moves into a suburban 'starter' tract house. They become increasingly disturbed by a presence that may or may not be somehow demonic which is mostly active in the middle of the night (7). (Figure2) 


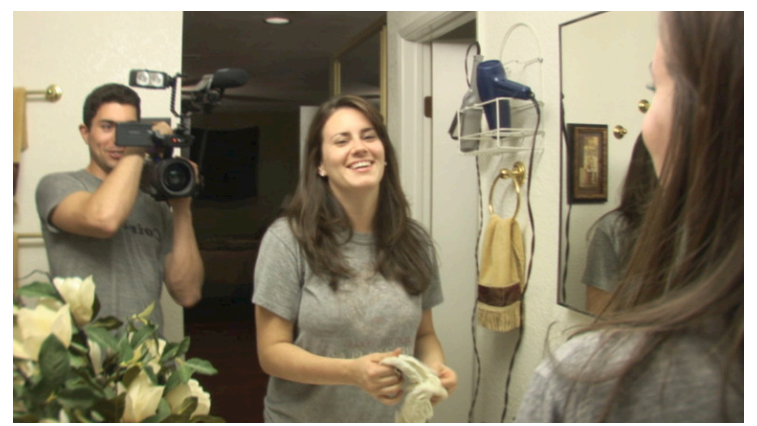

Figure 3. Still from Paranormal Activity.

http://kalafudra.wordpress.com/2011/02/12/paranormal-activity-2007/

In Paranormal Activity the film starts with a text saying: Paramount would like to thank to families of Micah Sloat and Katie Featherston and the San Diego Police Department. Instead of opening credits, by the help of this text, the filmmaker prepares the audience to an amateur approach. Starting from the first scene, the audience starts to see a shooting of an amateur, shaking camera. Also this shooting is more like an amateur testing the camera features. Then with the second scene, by the help of a mirror, we see the cameraman shooting himself. Normally with a classical narrative, which uses continuity editing style, we don't see this type of camera movement; unbalanced color temperature and a grainy look because of low light intensity. Also the cameraman uses the top light of the camera, which erases all shadows and makes a two dimensional look at the picture.(Figure 3) Almost all professional cinematographers know that front light causes this defect and they don't prefer to use that angle as a key light. Also because of inverse square rule the light intensity drops so fast at the image, the areas away from the camera look underexposed. The duration of the first shot is 1 minute 23 seconds, which is a pretty long time to control the pace. At the first cut, we cut from the medium shot of a woman who arrives at home to medium cut of the same women inside the house. This cut can be a good example to jump cut. The film looks like documenting supernatural incidents and the camera usage is like only documenting those incidents. During the movie there is almost no transition in between shots. Both the scenes, which have been shot by the actors and the scenes which were documenting the incidents are very similar to each other. Mostly these shots are point of view shots and these shots give the impression of an "amateur video". The story of the film was mostly made from the conversations of the young couple, and being followed by the "thing" during the day and night. Besides these actions, the audience can't see any living actions of the couple. That's why the way of using the film language makes the film interesting. Although this type of narrative is very different than classical narrative, the film was accepted as, successful by its audience. This way of story telling reminds most of them their past experiences with their consumer video cameras. This feeling increased their attention more and added up more reality to this horror movie. According to the Internet Movie Database (IMBD) the film's cost was 15,000 USD and made a worldwide gross of approximately 194,000,000 USD (7). 


\subsection{The case of District 9}

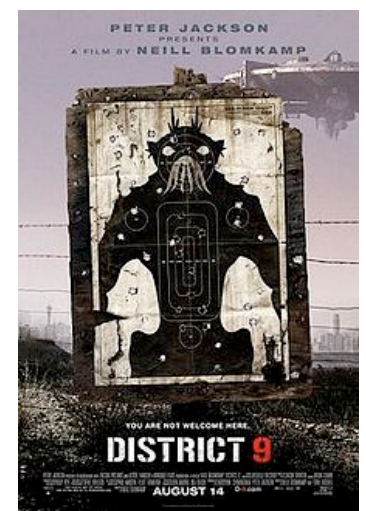

Figure 4. The poster of District 9

http://en.wikipedia.org/wiki/District 9

The storyline which was written by Kenneth Chrisholm explains the movie as: "In 1982, a massive star ship bearing an alien population, nicknamed "The Prawns", appeared over Johannesburg, South Africa. Twenty-eight years later, the initial welcome by the human population has faded. The refugee camp where the aliens were located has deteriorated into a militarized ghetto called District 9, where they are confined and exploited in squalor. In 2010, the munitions corporation, Multi-National United, is contracted to forcibly evict the population with operative Wikus van der Merwe in charge. In this operation, Wikus is exposed to a strange alien chemical and must rely on the help of his only two new 'Prawn' friends" (8). (Figure 4)

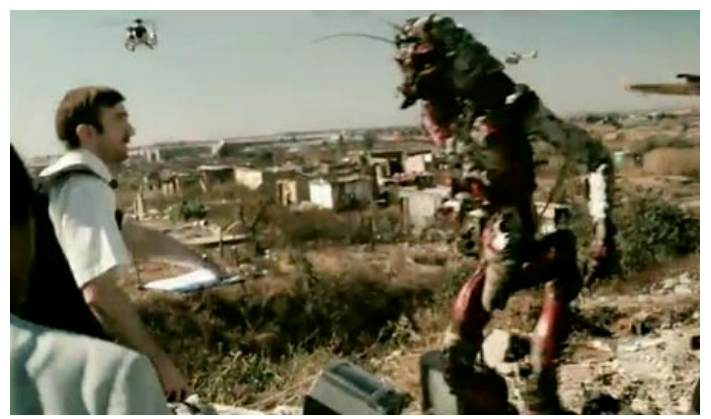

Figure 5. Still from District 9

http://ozgurilgin.wordpress.com/2010/02/21/yasak-bolge-9-district-9-2008/

The movie District 9 is quite different. Unlike Paranormal Activity, the film starts as a professional production and in the first scene we see the main character Vikus Van de Merwe seem like getting prepared for a TV interview. In the first shot we see an inappropriate zooming, which is done to find the right composition, in this case for the television interview. Also we see him trying to attach the microphone to his sweater while talking to the cameraman. In the first shot, he is shot at medium shot, the second one is medium close-up, third one is close-up, and then the fourth one is medium shot again. The camera position is the same in each shot. Actually these first four scenes are good examples to show jump cutting. He seems like getting bigger and smaller in the frame without the background being changed. In the fourth one the interview starts. Later during the film there is a cameraman assigned to document the evacuation of aliens from the camp they live in. (Figure 5) Although the film is closer to classical narrative than the other two samples, the shots, which are being screened all during the film, makes the film look like a semi-documentary. Those shots are like being recorded years ago and also they are being used as a reference. We also see lots of shaky camera movements and jump cuts till the end of the movie. The movie has an interesting story and very high quality cinematography. The way of visualization and especially the way of 
using digitalization are highly impressive. District 9 is an expensive production compared to Paranormal Activity. The total cost was 30,000,000 USD but the total worldwide gross was 115,500,000 USD (8).

\subsection{The case of Cloverfield}

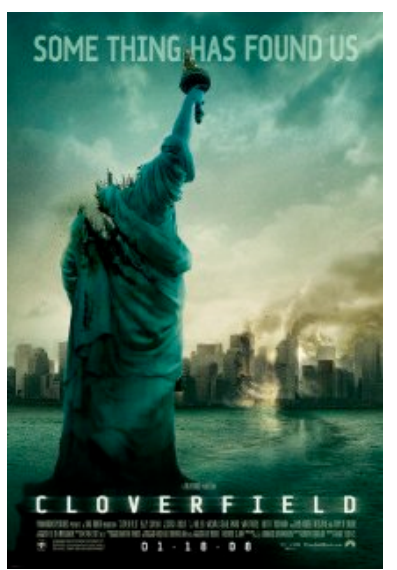

Figure 6. The poster of Cloverfield.

http://www.imdb.com/title/tt1060277/

The storyline which was written by Pip Carlson explains the movie as follows: "Cloverfield follows five New Yorkers from the perspective of a hand-held video camera. The movie is exactly the length of a DV Tape and a sub-plot is established by showing bits and pieces of video previously recorded on the tape that is being recorded over. The movie starts as a monster of unknown origin destroys a building. As they go to investigate, parts of the building and the head of the Statue of Liberty come raining down. The movie follows their adventure trying to escape and save a friend, a love interest of the main character" (9). (Figure 6)

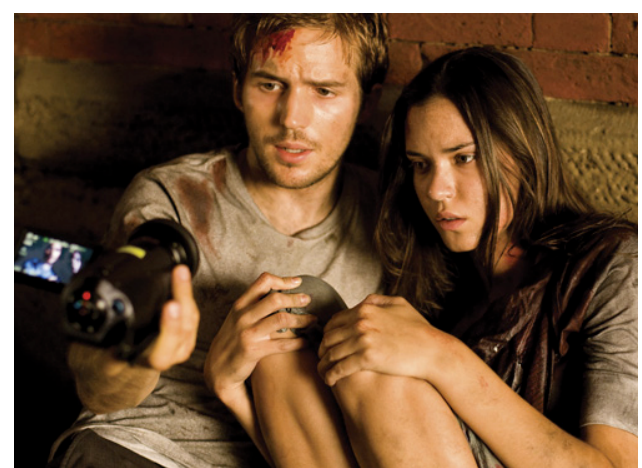

Figure 7. Still from Cloverfield.

http://moralpremise.blogspot.com/2010/10/cloverfield-in-pursuit-of-those-we-care.html

The film Cloverfield starts in a similar way to the movie Paranormal Activity. The opening credits inform us about the movie production soothe where audience already knows that it is a professional production. The film Cloverfield seems like being professionally produced. Just after the opening credits we see a color bar in the frame and we also see the time-code running at the bottom of the frame, which does not look professional. By the help of the written texts on the screen we are informed about the camera being somewhere in the Central Park. The image fades out. With the fade in, the time-code, which is running at the bottom of the page, disappears. This time at the left bottom of the frame we see the date stamp, which is only a feature for amateur cameras. Also the first image is underexposed and not color balanced. The person who carries the camera is shaking the camera while carrying it. Duration of the first shot is about a minute long which is quite long for a movie. During this 
shot, a male voice who seem like the person recording the footage, gives us information about the time and the place. During the cuts, matching almost never takes place. All during the film sometimes the actors are looking at the camera and talking. Besides that, some other times the camera seems like a candid camera intruding peoples' personal lives. The audience also hears the ambience noise like it is recorded by the camera microphones. The camera microphones are usually omni directional and record all the sounds equally. One other thing about the camera sound feature is auto gain control. This feature finds the strongest sound in the location and increases the recording sound levels accordingly. So when there is silence in the scene, the auto gain control automatically increases the ambience noise sound level and this voice becomes disturbing. Just like the other two films, in this film the camera usage is like documenting an incident by an amateur cameraman rather then telling a story. (Figure 7) This way of camera usage and editing seem like being accepted by the audience because Cloverfield was produced for $25,000,000$ USD and the worldwide gross was $170,000,000$ USD (9).

\section{CONCLUSION}

The purpose of using this 'new way' of story telling seems to be giving the audience a feeling of reality. That is why, the color balancing, exposure, composition, and match cutting, can be disregarded by some filmmakers, within this new way. Still today there are two ways of story telling in cinema; the first one is the classical narrative, which gives importance to lighting, framing and match cutting. And the new way of story telling, which denies almost all cinematographic elements for classical narrative. The purpose of both styles, are the same: to create an emotional effect on their audience, but they use completely opposite ways while telling their stories. The way of filmmaking has always been taught from the professionals to amateurs, but lately the direction of information seems to go backwards. By the help of the technology amateurs seem to create their own way of story telling. Instead of losing time with continuity editing, they choose to tell their stories in a much 'naïve' way, and this way of story telling seems to be accepted by the audience. May be the first time in film history the professionals started to use the same language while telling their stories. It seems like there will be a competition between these two styles and filmmakers will use the advantages of both film styles for a while. All three movies are good examples for the "amateur video" style. Their production, contents and genres make them eligible for using this new style easily. It can be seen in all three samples that horror, sci-fi and fantastic movies are more appropriate to visualize their content in this way rather than using the classical narrative or continuity editing. These type of movies are not produced in a traditional way of story telling and also during the visualization of their structure, they are produced by not using the tools of classical narrative such as classical continuity in editing, aesthetical self concern, framing, lighting and color. Therefore, it seems like the term "amateur video" is being defined as a new film language and this new approach is serving to the majority of movies especially with the genres of horror, sci-fi, and fantasy.

\section{REFERENCES}

Gross, L. S., Ward, L. W. (2000). Electronic Moviemaking. Belmont (USA): Wadsworth, Thomson Learning.

Reisz, K., Millar, G. (1989). The Technique of Film Editing. Focal Press.

Dancyger, K. (2002). The Technique of Film and Video Editing. Focal Press.

Sokolov, A. G. (1995). Sinemada Görüntü Kurgusu. Translated by S. Aslanyürek. İstanbul: Antrakt Yayınları.

Ascher, S., Pincus, E. (2007). The Filmmaker's Handbook. $3^{\text {rd }}$ edition. London: Plume, Pinguin Group.

Ball, J., Carman, R., Gottshalk, M., Harrington, R. (2010) From Still To Motion. Berkeley CA:New Riders, Peachpit, Pearson Education 
International Movie Database. Available at http://www.imdb.com/title/tt1179904/ (04 January 2012).

International Movie Database. Available at http://www.imdb.com/title/tt1136608/ (04 January 2012).

International Movie Database. Available at http://www.imdb.com/title/tt1060277/ (04 January 2012).

\section{APPENDIX}

Name of the film: "Paranormal Activity"

Production year: 2007

Country: USA

Production Company: Blumhouse Productions.

Running time: 86 min.

Director: Oren Peli

Genre: Horror

Budget: 15,000 USD

Logline: After moving into a suburban home, a couple becomes increasingly disturbed by a nightly demonic presence.

Name of the film: "District 9"

Production year: 2009

Country: USA, New Zeland, Canada, South Africa

Production Company: TriStar Pictures, Block / Hanson, WingNut Films

Running time: $112 \mathrm{~min}$.

Director: Neil Blomkamp

Genre: Action- Sci-Fi

Budget: 30,000,000 USD

Logline: An extraterrestrial race forced to live in slum-like conditions on Earth suddenly finds a kindred spirit in a government agent who is exposed to their biotechnology.

Name of the film: "Cloverfield"

Production year: 2008

Country: USA

Production Company: Paramount Pictures, Bad Robot

Running time: $85 \mathrm{~min}$.

Director: Matt Reeves

Genre: Horror, Fantasy

Budget: 25,000,000 USD

Logline: Revolves around a monster attack in New York as told from the point of view of a small group of people. 